\title{
The unforeseen orbital tumor
}

\author{
Srishti Singh, Bagyam Raghavan, Sivaramalingam Geethapriya, Jayaraj Govindaraj, G Padmanabhan, \\ Murali Krishna, Rasheed Arafath, V V Sathyasree \\ Department of Radiodiagnosis, Apollo Speciality Hospital, Chennai, Tamil Nadu, India
}

Correspondence: Dr. Srishti Singh, Department of Radiodiagnosis, Apollo Speciality Hospital, 320 Mount Road, Teynampet,

Chennai - 600 018, Tamil Nadu, India. E-mail: srisinghgkp@gmail.com

\begin{abstract}
Inflammatory myofibroblastic tumor is a rare group of neoplasms showing a mixture of spindle-shaped myofibroblasts or fibroblasts and a variable amount of inflammatory cells (eosinophils, plasma cells, and lymphocytes). They are not usually included in the differential diagnosis of nodules and masses because of their rarity, therefore, remaining an underdiagnosed entity. We report one such rare case in a 3-year-old female.
\end{abstract}

Key words: Inflammatory myofibroblastic tumor; myofibroblasts; rarity; underdiagnosed

\section{Introduction}

Knowledge regarding the uncommon tumors in head and neck region is of utmost importance in correlation with their sites of occurrence, imaging features, and histopathological analysis. Inflammatory myofibroblastic tumor (IMT) is one such atypical group of neoplasms which is an underdiagnosed entity. Many different terms have been used to refer to these tumors: plasma cell granuloma, inflammatory myofibrohistiocytic proliferation, fibroxanthoma, and xanthogranuloma. ${ }^{[1]}$ Clinical presentation of IMTs depends on the organ in which they arise, but they frequently associate general inflammatory symptoms as fever or malaise. Radiological appearance of IMTs is unspecific, and they are often misdiagnosed as malignant neoplasms. ${ }^{[1]}$

We report a unique case of a 3-year-old female who presented with complaints of right eye pain, redness, irritation, and mild proptosis in our OP department.

\section{Case History}

A 3-year-old female presented with complaints of right eye pain, redness, irritation, and mild proptosis in our

\begin{tabular}{|l|l|}
\hline \multicolumn{2}{|c|}{ Access this article online } \\
\hline Quick Response Code: & \\
\hline & Website: \\
\hline & www.ijri.org \\
\cline { 2 - 3 } & DOI: \\
& 10.4103/ijri.IJRI_73_20 \\
\hline
\end{tabular}

OP department. The patient was referred for MRI brain for further evaluation. MRI brain showed an extraconal lesion involving the inferior wall of right orbit, extending to lamina papyracea with minimal extension of the lesion into the anterior aspect of maxillary antrum [Figure 1]. The lesion was isointense to skeletal muscle on T1WI, hypointense on T2, and FLAIR sequences [Figure 1]. The lesion showed homogeneous enhancement on contrast imaging. The lesion displaced the right inferior rectus superiorly and closely abutted the medial rectus with no sign of invasion [Figure 1]. No intracranial extension was noted. Most common differential diagnosis of a T2 hypointense homogeneously enhancing intraorbital mass in pediatric age group are: a) intraorbital lymphoma, b) infantile fibromatosis, and c) xantho granulomatous lesion.

Excisional biopsy of the right orbital mass was done, and the specimen was sent for histopathological and immunohistochemical evaluation. The mass showed proliferation of spindle cells with keloid-like collagen.

This is an open access journal, and articles are distributed under the terms of the Creative Commons Attribution-NonCommercial-ShareAlike 4.0 License, which allows others to remix, tweak, and build upon the work non-commercially, as long as appropriate credit is given and the new creations are licensed under the identical terms.

For reprints contact: WKHLRPMedknow_reprints@wolterskluwer.com

Cite this article as: Singh S, Raghavan B, Geethapriya S, Govindaraj J, Padmanabhan G, Krishna M, et al. The unforeseen orbital tumor. Indian J Radiol Imaging 2020;30:386-8.

Received: $10-F e b-2020$ Accepted: $21-J u n-2020$

Revised: 03-May-2020 Published: $15-$ Oct-2020 


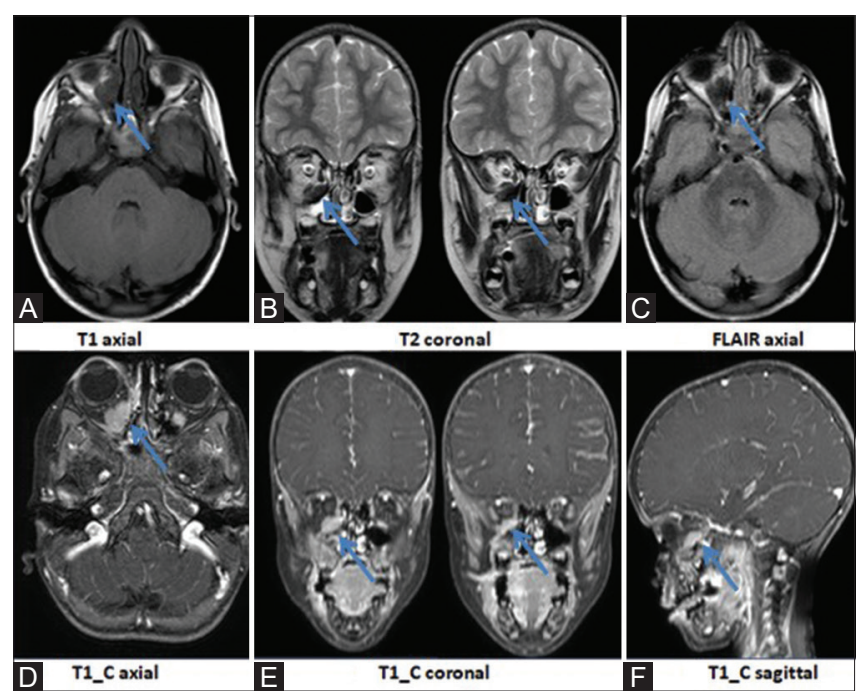

Figure 1 (A-F): An extraconal lesion was seen involving the inferior wall of right orbit, extending to lamina papyracea with minimal extension of the lesion into the anterior aspect of maxillary antrum (B and $C)$. The lesion appeared isointense on T1 (A), hypointense on T2 and FLAIR (B and $C)$. The lesion showed homogeneous enhancement on contrast imaging (D-F). The lesion displaced the right inferior rectus superiorly and closely abutted the medial rectus with no sign of invasion (B)(arrows)

Foamy histiocytes and focal lymphoid aggregates were also noted [Figure 2]. There was no evidence of atypical cells. Immuno histochemistry report was positive for vimentin, smooth muscle actin (SMA), and CD68, and negative for all other markers (CK, CD3, ALK1, STAT 6, CD34, Beta catenin, H caldesmon, and S-100) [Figure 2]. These features confirmed the diagnosis as inflammatory myofibroblastic tumor. The patient was managed accordingly and was started on corticosteroids to assess the interval response. The patient was also advised for regular interval follow up. However, the patient failed to show up for further response assessment and therefore further analysis of the status of the disease could not be done.

\section{Discussion}

Inflammatory myofibroblastic tumor is a rare group of neoplasms showing a mixture of spindle-shaped myofibroblasts or fibroblasts and a variable amount of inflammatory cells (eosinophils, plasma cells, and lymphocytes). ${ }^{[2]}$ Different etiologies have been proposed for IMT, being different chronic infections, autoimmune diseases and trauma are the most accepted. Specific inflammatory diseases, such as IgG4 disease, have also been recently associated ${ }^{[3]}$ The lungs, liver, and gastrointestinal tract are the most common sites for inflammatory myofibroblastic tumor. Less frequently they are seen in the head and the neck region, including the orbit. Diagnosis is usually based on the histologic examination of the lesions.

Predictors of malignant behavior are:

- Aneuploidy by flow cytometry.

- Frequent ganglion-like cells.

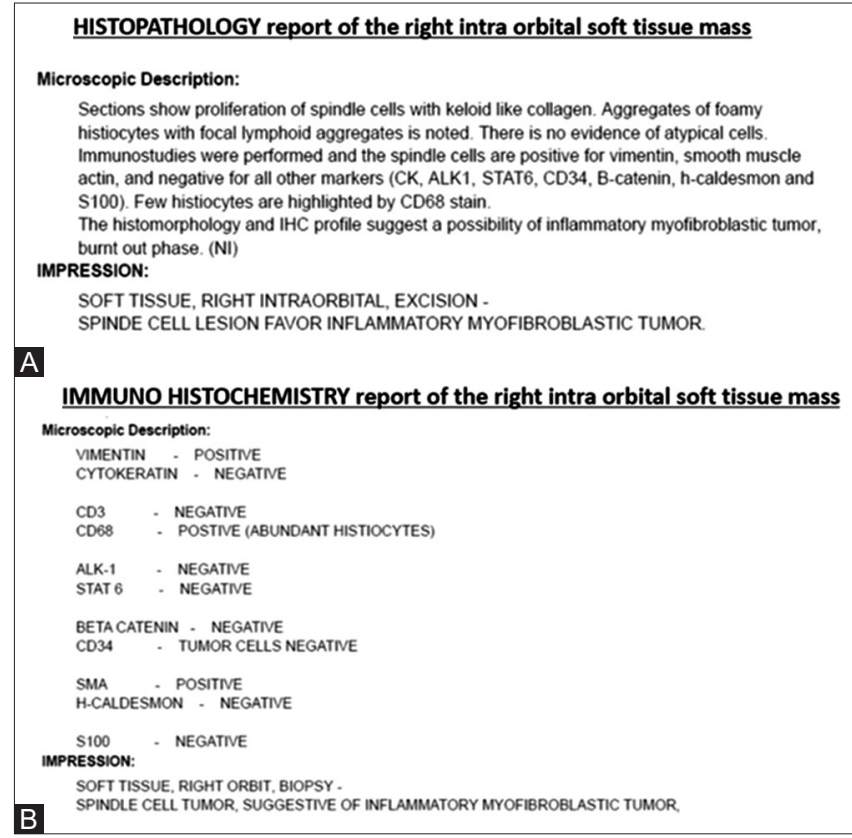

Figure 2 (A and B): (A) Histopathology and (B) immunohistochemistry reports of the right intraorbital soft tissue mass

- p53 positivity by immunohistochemistry.

- Cytogenic clonal abnormality overexpressing anaplastic lymphoma kinase (ALK), a receptor tyrosine kinase, suggesting a neoplastic cause. ${ }^{[4]}$

Intraorbital lesions usually present with pain, redness of eye, edema, proptosis, ptosis, diplopia, oculomotor deficits, swelling, and mass effects. ${ }^{[1]}$ Radiological findings include solid heterogeneously enhancing lesion that shows low signal intensity on T2-weighted imaging due to fibrotic component. Retrobulbar edema may be seen that appears hyperintense on T2 and SPIR images ${ }^{[2]}$ Differential diagnosis for this entity comprises granulomatous disease, primary infection, Sarcoid, Sjogren's disease, lymphoma, infantile fibromatosis, and connective tissue disorders..$^{[2]}$ Only after radiological and histological correlation could definitive diagnosis be achieved. The administration of corticosteroids usually leads to a decrease of size of the mass while sometimes radiotherapy or surgery may be indicated. Surgical resection in an intra orbital confirmed case of inflammatory myofibroblastic tumor can be considered in the cases refractory to treatment, and the cases showing malignant potential. However, lesions must be localized for best surgical outcome. For diffuse lesions near vital structures surgical resection may not be viable. ${ }^{[4]}$

\section{Conclusion}

Inflammatory myofibroblatic tumor is an under diagnosed entity as it is usually not included in the differential diagnosis of nodules and masses because of its rarity. 
It is imperative to know about the existence of such tumors, as they frequently have better treatment options and prognosis than the malignant neoplasms they are confused with.

\section{Declaration of patient consent}

The authors certify that they have obtained all appropriate patient consent forms. In the form the patient(s) has/have given his/her/their consent for his/her/their images and other clinical information to be reported in the journal. The patients understand that their names and initials will not be published and due efforts will be made to conceal their identity, but anonymity cannot be guaranteed.

Financial support and sponsorship

Nil.

\section{Conflicts of interest}

There are no conflicts of interest.

\section{References}

1. Chung EM, Smirniotopoulos JG, Specht CS, Schroeder JW, Cube R. Pediatric orbit tumors and tumorlike lesions: Nonosseous lesions of the extraocular orbit. RadioGraphics 2007;27:1777-99.

2. Cantera JE, Alfaro MP, Rafart DC, Zalazar R, Muruzabal MM. Inflammatory myofibroblastic tumours: A pictorial review. Insights Imaging 2015;6:85-96.

3. Kandpal H, Vashisht S, Sharma R, Seith A. Imaging spectrum of pediatric orbital pathology: A pictorial review. Indian J Ophthalmol 2006;54:227-36.

4. Patnana M, Sevrukov AB, Elsayes KM, Viswanathan C, Lubner M, Menias CO. Inflammatory pseudotumor: The great mimicker. AJR 2012;198:W217-27. 